\title{
FINANCIAL DESIGN FOR EMPLOYER ORGANISATIONS WITH A FOCUS ON MEMBER SATISFACTION*
}

\author{
DOI: 10.17261/Pressacademia.2021.1483 \\ PAP- V.14-2021(9)-p.38-41
}

\section{Basar Ay}

Istanbul Commerce University, Finance Institution, International Banking and Finance, İstanbul, Turkey. bay@tekstilisveren.org.tr, ORCID: 0000-0003-3865-9153

\section{To cite this document}

Ay, B. (2021). Financial design for employer organizations with a focus on member satisfaction. PressAcademia Procedia(PAP), $14,38-41$. Permanent link to this document: http://doi.org/10.17261/Pressacademia.2021.1483

Copyright: Published by PressAcademia and limited licensed re-use rights only.

\begin{abstract}
Purpose- The dynamics of industrial relations between workers and employers have changed dramatically as a result of changing competition conditions in international markets due to the global trend towards liberalization and globalization of supply chains. While massive worker unionization has started to decentralize, the employer organizations- that emerged as a response to labor unions- had to maintain their existence by offering services other than collective labor agreements to their members. This study, therefore, aims at proposing financial models to employer organizations for them to use their existing funds for activities to ensure member satisfaction, and thus keep their membership base.

Method- Global and Turkish concerning employer organizations have been compared and the stemming on their service possibilities have been analyzed. Fund allocation and services of an actual employers' association in Turkey has been examined as a case study. Also, a survey has been conducted among its members to measure their needs and expectations from the association.

Findings- Employer organizations' capacities for measuring their members' satisfaction level and expectations and for designing their services accordingly is an area to improve. On the other hand, the commercial activities they can conduct to grow their funds and their services spectrum using their funds are restricted by law.

Conclusion- The survey results indicate an obvious expectation from members for the employer organizations to use their funds to facilitate their access to finance and qualified human resources, so that they maintain their international competitiveness. The study proposes models for the employer organizations to grow their existing funds within the legal framework; as well as changes in regulations -where necessaryfort he advantage of members and the whole country.
\end{abstract}

Keywords: Financial design, employer organisations, satisfaction survey

JEL Codes: L00, D02, Y10

\section{IŞVEREN ÖRGÜTLERINDE ÜYE MEMNUNIYET ODAKLI FINANSAL TASARIM}

\section{ÖZET}

Amaç- İşçiler ve işverenler arasındaki endüstri ilişkilerinin dinamikleri; dünya ekonomisindeki liberalleşme eğilimi, tedarik zincirlerinde küreselleşme ve bunlara bağlı olarak değişen uluslararası rekabet ortamı neticesinde önemli ölçüde değişmiştir. Toplu işçi örgütlenmelerinde merkezileşme süreci tersine dönerken, işçi hareketine cevaben doğan işveren örgütleri de, üyelerine toplu iş sözleşmesi müzakereleri dışında hizmetler sunarak varlıklarını devam ettirmektedir. Bu çalışmanın amacı; sürdürülebilirlikleri, işverenlerin bir örgüt etrafında toplanmak konusunda istekliliklerine bağlı bu oluşumların, mevcut fonlarını üye memnuniyetine yönelik hizmetlerde kullanmaları için finansman modeli önerilerinde bulunmaktır.

Yöntem- Dünya ve Türkiye'deki işveren örgütleri karşılaştırmalı olarak mukayese edilmiş, bu örgütlerin verebileceği hizmetler analiz edilmiştir. Türkiye'den vaka çalışması olarak bir işveren sendikasının fon kullanımı ve üyelerine verdiği hizmetler incelenmiştir. Söz konusu sendikanın üyeleri genelinde bir anket çalışması yapılarak, sendikadan beklentileri ölçülmüştür.

Bulgular- İşveren örgütlerinin üye memnuniyeti ve ihtiyaçlarını ölçme ve hizmetlerini buna göre tasarlama kabiliyetlerinin gelişime açık olduğu anlaşılmıştır. Öte yandan, bu örgütlerin fonlarını büyütebilecekleri ticari faaliyetleri ve fonlarını kullanabilecekleri hizmet alanları yasal mevzuatla sınırlandırılmıştır.

Sonuç- Vaka çalışması kapsamında elde edilen anket sonuçları, işveren örgütlerinin ellerinde bulunan fonu, özellikle, üyelerin uluslararası rekabetçiliğini arttırmaya yönelik finansmana ve kalifiye insan kaynaklarına erişim için kullanmaları yönünde bir beklenti olduğunu ortaya koymuştur. Çalışma; işveren örgütlerinin -yasal çerçevenin izin verdiği ölçüde- ticari işletmeleri aracılığıyla üyelerine hizmet için kullanacakları fonu büyütmeleri için modeller ve gerekirse üyelerin ve ülkenin menfaatine olacak şekilde mevzuat değişikliği önerileri sunmaktadır.

Anahtar Kelimeler: Finansal tasarım, işveren örgütleri, memnuniyet anketi

JEL Kodları: L00, D02, Y10

\footnotetext{
* Bu çalışma İstanbul Ticaret Üniversitesi Finans Enstitüsü Uluslararası Bankacılık ve Finans Yüksek Lisans programı kapsamında yazılan

"işveren Sendikalarında Üye Memnuniyet Odaklı Finansal Tasarım: Kurumsal Yapılanma Modeli" adlı tezden üretilmiştir.
} 


\section{GíRiş}

Ulusal ve uluslar üstü düzeylerde sosyal diyalogda işveren örgütlerinin merkezi rolü, uluslar üstü kurumlar tarafından savunulmakta ve desteklenmektedir. Yine de, özellikle Batı Avrupa dışındaki bazı kuruluşlar, üyelik ve gelir yaratma konusunda önemli zorluklarla karşı karşıyadır. Iş̧̧i ve işveren örgütleri, endüstri ilişkilerinin iki önemli tarafı olsa da; literatür daha çok ilki üzerine odaklanmış, ikinci aktör ile ilgili çok fazla akademik çalışma yapılmamıştır. Bunun sebebinin işveren örgütlerinin savunmacı ve tutucu politikalarının, iş̧̧ sendikalarının daha tuttuğunu koparan siyasi hareketi kadar ilgi çekici olmaması olarak açıklanabilir (Mclvor, 1996, s. 3). Bu tezin amaçlarından biri, hakkında yeterince akademik çalışma yapılmamış işveren örgütlerine ışık tutmaktır. Sanayi Devrimi'nin getirdiği çalışma koşulları, işçilerin haklarını toplu olarak bir örgüt etrafında korumak amacıyla sendikalaşmaya zemin hazırlamıştır. İş̧i sendikalarının sıklıkla başvurduğu bir yöntem olan grevlere karşı işletmelerini korumak isteyen işverenlerin örgütlenmesi ise iş̧̧i hareketine cevaben 19. Yüzyılda gerçekleşmiştir. İkinci Dünya Savaşı sonrası endüstrileşme döneminde zirve yapan endüstri ilişkileri, 20. Yüzyılın sonlarına doğru liberalleşme, küreselleşme ve bunların getirdiği uluslararası rekabet döneminde farkı ekonomik düzenlerde farklı formlar kazanmıştır.

Toplu işçi hareketlerinde merkezileşme sürecinin tersine dönmesi ve toplu sözleşmelerin ulusal düzeyden, endüstri ve şirket düzeyine indirilmesi ve işçilerin bireysel hareketlerindeki artışla işçi hareketinin gücü ve yoğunluğu azalırken; işveren sendikaları ana görevleri olan toplu iş görüşmelerinin yanına, üyeleri için başka hizmetler ve görevler ekleyerek varlıklarını sürdürmeyi başarmışlardır. Genel olarak dünyada, işverenlerin bir örgüt etrafında toplanmak konusunda isteklerinin azaldığına dair bir eğilim gözlemlenmemiştir.

Türkiye'de de bildiğimiz sendikal anlamda işverenlerin örgütlenmesine zemin sağlayan endüstriyel ve ekonomik şartlar 20. Yüzyılın ikinci yarısında oluşmaya başlamış olup; 1960'ların başı işveren sendikaları için bir milat sayılmaktadır. Ülkenin kendi dinamikleri yanında özellikle 1980'den sonra dünyadaki küreselleşme ve liberalleşme rüzgârlarının da etkisiyle, dünyadakine benzer bir düşüş trendi Türkiye'de de görülmüş̧; Türk işveren sendikaları da dünyadaki benzerleri gibi kendilerini ve hizmetlerini yenileyerek dönüştürmüşlerdir.

Bu bağlamda çalışmada, sürdürülebilirlikleri, işverenlerin bir örgüt etrafında toplanmak konusunda istekliliklerine bağlı bu oluşumların, mevcut fonlarını üye memnuniyetine yönelik hizmetlerde kullanmaları için oluşturmak amaçlanmaktadır.

\section{ISSVEREN ÖRGÜTLERI}

Tarih boyunca bu iki tarafın birbirleri ile olan güç ilişkisi ekonomik atmosfere göre birinin elinin daha güçlü olması, diğerinin güçlü tarafla uzlaşmak durumunda kalması olarak sürmüştür. Kabaca; endüstriyel ve ticari faaliyetin yoğun olduğu ekonomik büyüme dönemlerinde iş gücü piyasasındaki darlık ve yetersizlikten dolayı iş̧̧ tarafının pazarlık gücü daha yüksekken; işsizliğin zirve yaptığı ekonomik durgunluk dönemleri ise işveren tarafının elini güçlendirecek şartları sağlamıştır (Mclvor, 1996, s.183).

$A B^{\prime}$ de işveren örgütlerinin geçmişine bakıldığında hemen hemen AB'nin kendisi kadar eski oldukları görülmektedir. Bugünkü Avrupa Birliği'nin temeli olan Avrupa Kömür ve Çelik Topluluğu'nun 1952'de kurulmasıyla altı kurucu ülke olan Almanya, İngiltere, İtalya, Belçika, Hollanda, Lüksemburg'un sanayicilerinin temsilcileri de bir araya gelerek bir federasyon kurmuş, 2. Dünya Savaşı́nın yıkıcılığından sonra yeniden yapılanmakta olan Avrupa'nın endüstriyel gelişimine ortak katkı sunmayı hedeflemişlerdir. Avrupa Endüstri Federasyonları Konseyi (Conseil des Fédérations Industrielles d'Europe /CIFE) olarak doğan örgüt, $A B^{\prime}$ nin genişlemesiyle büyümüş ve bugünkü BusinessEurope (Avrupa İşadamları Konfederasyonu) adını almıştır. Avrupa Sosyal Diyaloğu'nun önemli bir parçası olan bu örgüt, AB'nin sosyal ve sanayi politikaları hakkında Avrupa Komisyonu'na görüş bildirmekte, üyelerinin çıkarlarını bu yolla temsil etmektedir. Croucher, Tyson ve Wild (2006) çalışmasında, Batı Avrupa modellerinin en iyi uygulama modeli olarak ne kadar kullanılabileceğini incelemektedir. Uluslararası veriler, Batı Avrupa modellerinin yalnızca katı koşullar altında örnek olarak kullanılması gerektiğini önermek için analiz edilmektedir. Çünkü bu modeller daha bağlama duyarlı bir yaklaşım gerekliliği barındırmaktadır. Ayrıca, yüksek düzeyde devlet desteğine dayalı önlemler örgütsel bağımsızlık için tehdit oluşturabileceği vurgulanmıştır.

$A B D^{\prime}$ de işveren örgütlerinin rolü daha kısıtıdır. Çatı işveren örgütü, ana görevi toplu sözleşmeden ziyade iş dünyasının piyasadaki genel çıkarlarını korumak olan ve 20. Yüzyılın başlarından itibaren faaliyet gösteren Amerikan Ticaret Odası'dır. ABD'de endüstri ilişkilerinin hukuki çerçevesine bakıldığında; 1930 'lara kadar sendikal özgürlüğün kısıtlandığı, mahkemelerin daha çok işveren lehine kararlar verdiği, toplu sözleşmenin hak olarak görülmediği bir ortam görülmektedir. 1932 yılında Başkanlığa gelen Franklin Roosevelt; Büyük Buhran sonrası ülkeyi ekonomik olarak ayağa kaldırmayı hedefleyen reformlar kapsamında Wagner Yasası olarak bilinen Ulusal iş̧gücü ilişkileri Yasası (National Labor Relations Act) ile sendikal harekete alan açmıştı (Kaya, 2017, s. 17). Wagner Yasası ABD'de, işçi ve işveren tarafını eşit taraflar olarak kabul eden ilk yasa olan 1935 tarihli Wagner Yasası şunlara izin vermektedir:

$\checkmark$ Closed shop: bir çalışanın istihdam edilmek için sendikaya üye olmasının zorunlu olduğu işyeri

$\checkmark \quad$ Union shop: çalışanın sendikaya üye olmadan istihdam edilebildiği, fakat belli bir süre içinde üye olmayı taahhüt ettiği iş yeri

$\checkmark$ Agency shop: çalışanın sendikaya üye olmak zorunda olmadığı, fakat temsil aidatını ödemek zorunda olduğu iş yeri

$\checkmark$ Open shop: çalışanın sendikayla ilgili hiçbir şeye zorlanamayacağı iş yeri.

ABD'de bugünkü sendikal yapıya bakıldığında kamu iş̧̧i sendikalarında "open shop" prensibinin geçerli olduğu, yani sendikal bir zorlamanın olmadığı; özel sektörde ise hala "agency shop" yani sendikalı olmayan işçilerin de temsil ücreti ödediği sistem görülmektedir.

Asya'da işveren örgütleri hususunda en önemli örnek Çin'dir. Planlı ekonomilerde iş̧̧i ve işverenlerde örgütlülük seviyesi oldukça yüksek olup, gönüllülük değil zorunluluk esasına dayanmaktadır. Çin'in geleneksel ekonomik yapısı böyle olsa da, son on yıllarda çok uluslu şirketlerin Çin pazarına ticaret ve yatırım gibi sebeplerle girmesiyle, işçi-işveren ilişkilerinde Batı'da bilinen pratikler görülmeye başlanmıştır. Yine de günümüzde işveren ve işçi örgütlerinin endüstri ilişkileri kapsamındaki görevleri yüzeysel kalmakta; sendikalar işçi ya da işverenlerin değil, devletin çıkarına hizmet ettiklerine yönelik eleştirilmektedir. Özellikle ücret belirlenmesi ve anlaşmazlıkların çözümünde devlet otoritelerinin etkin olduğu gözlemlenmektedir. Bu sebeple, tarafların eşitliği prensibine dayalı bir üçlü sosyal yapıdan bahsetmek henüz mümkün değildir. Örneğin literatür incelendiğinde Japonya, Güney Kore, Singapur ve Hong Kong gelişmiş ülkeler kategorisinde; Malezya, Çin, Vietnam, Hindistan, Endonezya gelişmekte olan ülkeler kategorisinde işveren örgütleri bakımından incelenmektedir. Bu ülkeler arasından Çin, diğer örneklerin aksine planlı ekonominin en uç örneklerinden biri olduğundan karşılaştırma için seçilmektedir (Benson, Zhu, ve Gospel, 2017).

Türkiye de ise işveren örgütlenmesi ahilik kültürüne kadar dayandırılabilse de işyerlerinde yasal örgütlenmenin yolunu açan ilk düzenleme ise 1947 tarihli Sendikalar Kanunu'dur. Buna rağmen 1960'lara kadar işveren düzeyinde kapsayııı bir örgütlenme görülmemektedir. Farklı 
sektörlerdeki müteşebbislerin bir işveren sendikası etrafında örgütlenmeye başlamasının 1960'ların başına denk gelmesi genelde 1961 Anayasası'nın getirdiği yeni düzenlemelerle açıklanmaktadır (Tekerek, 2019, s. 616). İstanbul'da kurulan ve henüz kendileri de çok genç olan Madeni Eşya Sanayicileri Sendikası, Tahta Sanayii İşverenleri Sendikası, Tekstil Sanayii İşverenleri Sendikası, Gıda Sanayii İşverenleri Sendikası, Matbaacılık Sanayii İşverenleri Sendikası ve Cam Sanayii İşverenleri Sendikası 1961 yılında bir araya gelerek İstanbul İşveren Sendikaları Birliği'ni kurmuşlar; daha sonra bu birlik Türkiye İşveren Sendikaları Konferderasyonu (TiSK) halini almıştır. Günümüzde, sendikal ilişkiler ve iş sözleşmesi konuları 2012 tarih ve 6356 sayılı Sendikalar ve Toplu İş Sözleşmesi Kanunu ile düzenlenmektedir. Bu kanunun 26. Maddesi sendikaların faaliyetlerinin yasal çerçevesini çizmektedir. Buna göre Sendikalar;

$\checkmark \quad$ Ticaretle uğraşamazlar, ancak genel kurul kararıyla nakit mevcudunun yüzde kırkından fazla olmamak kaydıyla sanayi ve ticaret kuruluşlarına yatırımda bulunabilirler;

$\checkmark \quad$ Elde ettikleri gelirleri üyeleri ve mensupları arasında dağıtamazlar;

$\checkmark \quad$ Üyelerine ancak grev ve lokavt süresince ve diğer zamanlarda eğitim amaçlı yardım yapabilirler.

Böylece, küresel ekonomik krizin yaşandığı 2009'den itibaren tartışılan, sendikaların biriken bütçelerini karşılıksız olarak üyelerine destek olarak dağıtma önerisi o günkü şartlar altında kabul görmemiştir (Canbolat, 2015, s. 175). Daha sonra, özellikle İşveren Sendikalarının girişimi ile 2014'te 6356 sayılı Kanunun ilgili maddesine aşağıdaki fıkra eklenmiştir: “işseren sendikaları, tüzüklerinde hüküm bulunmak ve şartları genel kurul kararıyla belirlenmek kaydıyla, işçilerin sigorta primlerinin işveren payının ödemelerinde kullanılmak ve nakit mevcudunun yüzde yirmi beşini aşmamak üzere karşılıksız yardıma dayalı dayanışma ve yardım fonu oluşturabilir."

\section{VERI VE YÖNTEM}

Çalışmada, sendika üyelerine uygulanmak üzere üye memnuniyet anketi oluşturulmuş, seçilmiş bir sendikanın üyelerine Eylül-Ekim 2021 döneminde yüz yüze görüşme tekniği ile uygulanmıştır. İlgili sendikanın 70 üyesi bulunmakla beraber 40 üyenin aktif olduğu belirlenmiş ve 30 üyeye ulaşılabilmiştir. Elde edilen veriler demografik açıdan sınıflandırılmış ve frekans analizi ile sonuçlar elde edilmiştir.

\section{BULGULAR}

Üyelere uygulanan anket sonucunda katılımcı işletmelerin çalışan sayısı bakımından büyüklüklüleri incelendiğinde \%43'ünün 100 ila 499 arasında kişiyi istihdam ettiği belirlenmiştir. Finansal bir tasarım için veri toplamak amacıyla oluşturulmuş anket sonuçlarından bu çalışmada sadece yönetim ve organizasyon ile finansman hususunda işletmeler için en önemli olan hususlara ilişkin istatistiksel sonuçlar paylaşılmaktadır. Katılımcı işletmelerin yönetim ve organizasyon hususunda çalışan mutluluğu ve performans yönetimini en önemli eksiklik olarak nitelendirdikleri tespit edilmiştir. İşletmeler bu sorunun aşılması için İşçi sendikaları ile birlikte motivasyon artırıcı etkinlikler yapılmasının çalışanlar üzerinde pozitif etki yaralatacağını belirtmiştir. Ayrıca iç denetim ve kalite sistemi eksikliğinin giderilmesi için konuya ilişkin yaşanan gelişmeler ve mevcut yapı hakkında sendikanın işletmelere yönlendirici faaliyetlerde bulunması önermişlerdir. İşletmeler için üçüncü en önemli eksiklik olan Kurumsallaşma hususunda kaydetmiş şirketlerin öykülerinin paylaşıldığı toplantıların tecrübe aktarımı için önemli olduğu vurgulanmıştır.

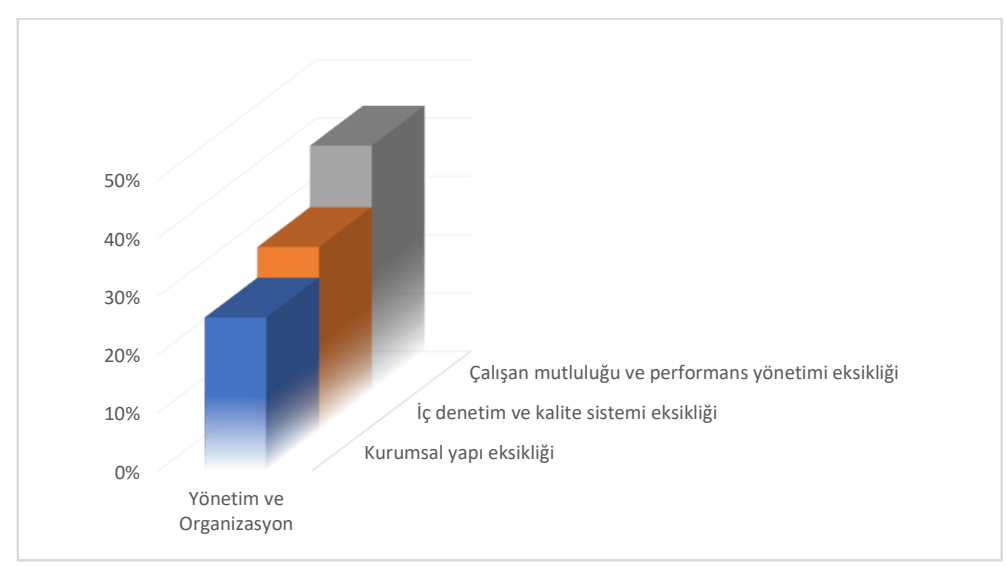

İşletmelerin Finansman hususunda en önemli zorluğu/eksikliği ise alternatif finansman kaynakları hakkında bilgi eksikliği olarak belirlenmiştir. Üye oldukları işveren örgütünün özellikle bu hususta bilgilendirici eğitim/toplantı/çalıştaylar düzenlemesi önem arz ettiği öneri olarak belirtilmiş ve finansman kaynakları ile İletişim hususunda sendikaların katalizör görevi görmesinin önemi vurgulanmıştır. Öte yandan uygun finansman kaynaklarına erişim hususunda işletmelerin izleyebileceği bir yol haritası oluşturulması da finansman hususunda yaşanacak sıkıntıların ortadan kaldırılmasına destek sağlayabilir. Katılımcı işletmelerin finansman sorunları hususunda çözüm beklentileri arasında sendikaların yeni yatırımlar için direkt finansman sağlayabileceği modeller geliştirilmesi de ifade edilmektedir. 


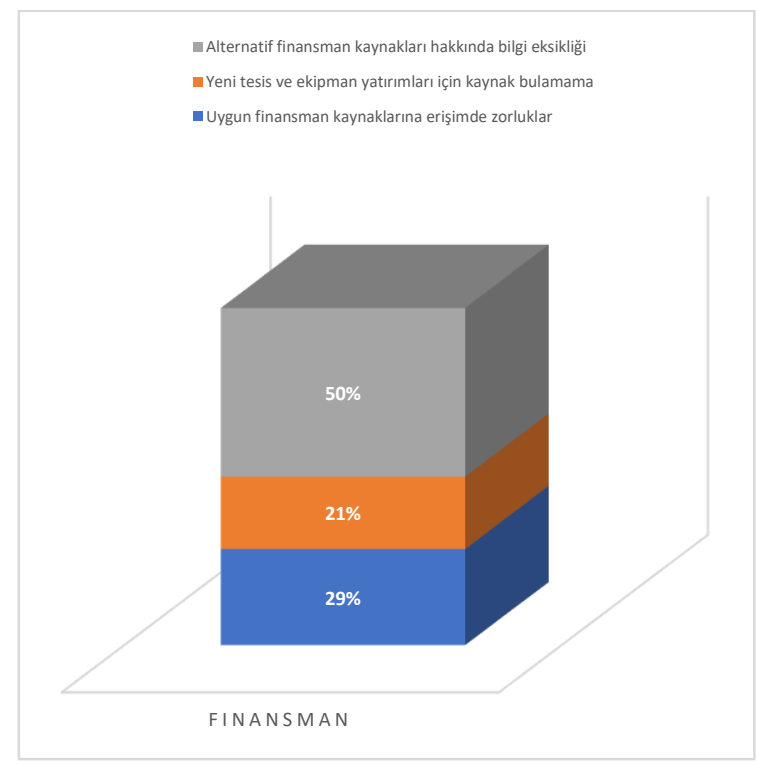

İşveren örgütlerinin üye memnuniyeti ve ihtiyaçlarını ölçme ve hizmetlerini buna göre tasarlama kabiliyetlerinin gelişime açık olduğu anlaşılmıştır. Öte yandan, bu örgütlerin fonlarını büyütebilecekleri ticari faaliyetleri ve fonlarını kullanabilecekleri hizmet alanları yasal mevzuatla sınırlandırılmıştır.

\section{SONUÇ}

Vaka çalışması kapsamında elde edilen anket sonuçları, işveren örgütlerinin ellerinde bulunan fonu, özellikle, üyelerin uluslararası rekabetçiliğini arttırmaya yönelik finansmana ve kalifiye insan kaynaklarına erişim için kullanmaları yönünde bir beklenti olduğunu ortaya koymuştur. Çalışma; işveren örgütlerinin -yasal çerçevenin izin verdiği ölçüde- ticari işletmeleri aracıllğıyla üyelerine hizmet için kullanacakları fonu büyütmeleri için modeller ve gerekirse üyelerin ve ülkenin menfaatine olacak şekilde mevzuat değişikliği önerileri sunmaktadır. Üyelerin yönetim ve organizasyon ile finansman hususunda yaşadıkları sorunlara/eksikliklere/zorluklara yönelik olarak sendikalarından beklentileri; eğitim, etkinlikler ile finansal iletişim ve/veya destek balıkları altında toplanabilmektedir.

\section{KAYNAKÇA}

Benson, J., Zhu, Y. ve Gospel, H. (2017). Employers' Associations in Asia. Londra: Routledge.

Canbolat, T . (2015). İşveren Sendikalarınca Kurulacak Yardım Fonlarına Iliş̧kin 6552 Sayılı Kanunla Getirilen Düzenlemenin Esasları. İ̧̧ ve Hayat, 1 (1), 171-180.

Croucher, R., Tyson, S., \& Wild, A. (2006). 'Peak'Employers' Organizations: International Attempts at Transferring Experience. Economic and Industrial Democracy, 27(3), 463-484.

Mclvor, A. (1996). Organised Capital: Employer Associations and Industrial Relations in Northern England. Cambridge: Cambridge University Press

Sheldon, P., Paoletti, F. ve Nacumulli, R., (2009). Clients or members? Organisational strategies of employer associations in Australia and Italy in response to industrial relations decentralisation. Uluslararası Endüstri Ilişkileri Derneği IIRA 15. Dünya Kongresi içinde. Sydney: 24-27 Ağustos 2009.

Tekerek, M. (2019). Türkiye'de İşveren Sendikacılığının Seyri. Ankara Üniversitesi SBF Dergisi, 74 (2), 601 - 629

Kaya, A. (2017). Toplu iş̧ Sözleşmelerinde Ehliyet ve Yetki. Yüksek Lisans Tezi. Hacettepe Üniversitesi SBÜ/ Özel Hukuk Ana Bilim Dalı,Ankara. 